\title{
MICROWAVE AGAINST THERMAL TREATMENT FOR MANUFACTURING OF ACTIVATED CARBON FROM AGRICULTURAL WASTES AND ITS USE TO ADSORB METHYLENE BLUE - EQUILIBRIUM AND KINETIC STUDIES
}

\author{
Hossam Altaher ${ }^{1,2}$, Fahd M. AL-Oufi ${ }^{1}$, Yehia H. Magdy ${ }^{3}$, Manar Hassan ${ }^{4}$ \\ 1_Department of Chemical Engineering Technology, Yanbu Industrial College, Saudi Arabia \\ 2_University of Nizwa, Department of Chemical and Petrochemical Engineering, Sultanatie of Oman \\ 3_Department of Chemical Engineering, Faculty of Engineering, El-Minia University, Egypt \\ 4 _National Institute of Laser Enhanced Science, Cairo University, Egypt \\ Email address: haltaher@hotmail.com
}

\begin{abstract}
Dates pits, a widely available agricultural waste, was used to produce two samples of activated carbon. The first sample was prepared by thermal treatment at $500{ }^{\circ} \mathrm{C}$ for two hours, and the other one was prepared through microwave irradiation for 12 minutes. Zinc chloride was used as the chemical activator for the two samples. The efficiency of the two samples towards methylene blue adsorption was investigated. The effects of some parameters, such as initial $\mathrm{pH}$ of the solution, initial concentration of methylene blue, contact time and adsorbent dose, on the adsorption capacity were also investigated. Equilibrium and kinetic models were applied to understand the mechanism of the adsorption process. The results showed that the preparation using the microwave radiation enhanced the adsorption capacity by $30 \%$. The concentration of the dye solution and its $\mathrm{pH}$ had significant effects on the adsorption. The optimum $\mathrm{pH}$ for adsorption was found to be 11. The experimental data was found to best fit Langmuir adsorption isotherm and pseudo second order kinetic model. Both pore diffusion and film diffusion were found to control the adsorption process.
\end{abstract}

Keywords: Adsorption, Date Pits, Equilibrium, Kinetics, Microwave, Models.

\section{INTRODUCTION}

Adsorption is one of the most important techniques that can be used for the treatment of water and wastewater because of its convenience, easy operation and simplicity. Moreover, this process also involves the treatment of different types of pollutants present in water or wastewater [1]. Some of the widely used adsorbents include activated carbon [2 - 4, ion exchange resins [5], metal oxides [6], hydroxides [7], carbonates [8], activated alumina [9], clays [10], agricultural wastes [11] and industrial solid wastes [12].
Activated carbon is preferred over other adsorbents due to its high porosity and high specific area [13], which leads to its high adsorption capacity for many pollutants present in water and wastewater. Several precursors have been tested for the production of activated carbon. However, agricultural wastes are highly preferred because of their wide availability, cheapness, renewability, and biodegradability [14]. Many studies have been conducted on the use of coconut shells [15], oil palm shells [16], corncob [17], almond shells [2], apple pulp [18], and rice husk [19] as precursors. 
Activated carbon can be produced from its precursor by physical activation (using steam or $\mathrm{CO}_{2}$ ) or chemical activation (using chemical substances like $\mathrm{ZnCl}_{2}, \mathrm{H}_{3} \mathrm{PO}_{4}$, $\mathrm{H}_{2} \mathrm{SO}_{4}$ ) at high temperature. This temperature is provided by regular heating furnaces or microwave ovens. This latter technique has proved its efficiency as it increases the yield of activated carbon production, increases the adsorption capacity of the produced activated carbon, and reduces the burning time, which saves energy [16].

As per FAO [20], the major date producing countries are Egypt (1,352,950 metric tons), Saudi Arabia (1,078, 300 metric tons), Iran $(1,023,130$ metric tons), UAE $(775,000$ metric tons) and Algeria (710,000 metric tons) [21]. Since the stone of the dates account for about $10 \%$ of the fruit's weight [22], the production of activated carbon from such precursor, i.e., dates pits, can be considered to be economically feasible [22-24]. However, more investigations are required to study the effect of different preparation conditions on the properties of activated carbon using microwave as the heating source.

Synthetic dyes are extensively used in many industries, such as textile industry [25], tanning of the leather [26], food technology [27], etc., which account for its presence in the wastewater. The estimated amount of dye produced every year is over 10,000 tons. The losses are estimated to be $1-2 \%$ in production and $1-10 \%$ loss in use. For reactive dyes, this figure can be about $4 \%$ [28].

The aim of this paper is to study the adsorption equilibrium and kinetics of methylene blue dye on activated carbon. The activated carbon was prepared using zinc chloride as the chemical activator and microwave radiation as the source of heating energy. The batch studies were performed to investigate the influence of different conditions that may affect the adsorption process. Different equilibrium and kinetic models were evaluated to describe the adsorption process. The results of these experiments would be useful for further applications in the treatment of wastewater containing methylene blue as a pollutant.

\section{MATHEMATICAL MODELS}

\subsection{ADSORPTION ISOTHERMS}

The equilibrium data were fitted to several isotherm models to establish the most appropriate correlation for the adsorption system. The least square regression method was used to fit the equations of these models to experimental data. The fitting of the data is given in terms of correlation coefficient $\mathrm{R}^{2}$.

The chi-square test represents the non-linear regression of the data. $x^{2}$ is calculated by the following equation:

$x^{2}=\sum\left(q_{e}-q_{e, m}\right)^{2} / q_{e, m}$

where, $\mathrm{q}_{\mathrm{e}, \mathrm{m}}$ is the equilibrium capacity obtained from model $(\mathrm{mg} / \mathrm{g})$, and $\mathrm{q}_{\mathrm{e}}$ is the experimental data of the equilibrium capacity $(\mathrm{mg} / \mathrm{g})$. If the data from the model are similar to the experimental data, $x^{2}$ will be a small number. If the data are different, $x^{2}$ will be a bigger number.

Langmuir isotherm [29]:

The non-linear and linear forms of this model are given by equations $2 a$ and $2 b$, respectively:

$q_{e}=\frac{q_{m} k_{L} c_{e}}{1+k_{L} c_{e}}$
$C_{e} / q_{e}=\left(1 / q_{m}\right) C_{e}+1 /\left(q_{m} K_{L}\right)$

where, $\mathrm{C}_{\mathrm{e}}(\mathrm{mg} / \mathrm{L})$ is the equilibrium concentration, $\mathrm{q}_{\mathrm{e}}(\mathrm{mg} / \mathrm{g})$ is the dye uptake at equilibrium, $\mathrm{q}_{\mathrm{m}}(\mathrm{mg} / \mathrm{g})$ is the maximum adsorption capacity, and $\mathrm{K}_{\mathrm{L}}(\mathrm{L} / \mathrm{mg})$ is a constant related to adsorption rate. The favorability of the adsorption is given by the 
dimensionless separation factor $R_{L}$, which is given by equation 3 :

$$
R_{L}=1 /\left(1+K_{L} C_{o}\right)
$$

where, $C_{o}(\mathrm{mg} / \mathrm{L})$ is the initial dye concentration. The value of separation factor $\left(\mathrm{R}_{\mathrm{L}}\right)$ indicates the favorability of the adsorption process as follows:

Unfavorable $\left(\mathrm{R}_{\mathrm{L}}>1\right)$, linear $\left(\mathrm{R}_{\mathrm{L}}=1\right)$, favorable $\left(0<\mathrm{R}_{\mathrm{L}}<1\right)$, and irreversible $\left(\mathrm{R}_{\mathrm{L}}=0\right)$. Freundlich isotherm [30]:

The non-linear and linear forms are given by equations $4 \mathrm{a}$ and $4 \mathrm{~b}$, respectively:

$$
\begin{aligned}
& q_{e}=k_{f} C_{e}^{1 / n} \\
& \ln q_{e}=\ln k_{f}+1 / n\left(\ln C_{e}\right)
\end{aligned}
$$

where, $\mathrm{q}_{\mathrm{e}}$ and $\mathrm{C}_{\mathrm{e}}$ have the same designation as Langmuir equation, and $\mathrm{k}_{\mathrm{f}}$ is a constant related to the bonding energy. $\mathrm{K}_{\mathrm{f}}(\mathrm{mg} / \mathrm{g}$ ( $\mathrm{L}$ $\mathrm{mg})^{1 / \mathrm{n}}$ ) can be defined as the adsorption coefficient, and $1 / \mathrm{n}$ is identifying the adsorption intensity of dye onto adsorbent. If the value of exponent $\mathrm{n}$ is greater than 1 then the adsorption represents favorable adsorption condition.

Dubinin-Radushkevich isotherm [31]:

The non-linear and linear forms of this model are given by equations $5 \mathrm{a}$ and $5 \mathrm{~b}$, respectively:

$q_{e}=q_{m} \exp \left(-B \varepsilon^{2}\right)$

$\ln q_{e}=\ln q_{m}-B \varepsilon^{2}$

where, $\mathrm{q}_{e}$ is the amount of adsorbate adsorbed onto adsorbent surface $(\mathrm{mg} / \mathrm{g}), \mathrm{q}_{\mathrm{m}}$ represents the maximum adsorption capacity of adsorbent $(\mathrm{mg} / \mathrm{g})$, and B is constant related to the mean free energy of adsorption per mole of adsorbate as it is transferred to the surface of the solid from infinite distance.

The Polanyi potential is given by:

$\varepsilon=R T \ln (1+1 / C e$,

$E=1 /(B)^{0.5}$

where, $\mathrm{R}$ is the ideal gas constant in $\mathrm{kJ} / \mathrm{mol} . \mathrm{K}$ and $\mathrm{T}$ is the temperature $(\mathrm{K})$.

\subsection{KINETIC MODELS}

The study of the kinetics of the adsorption provides important data related to the adsorption process. It estimates the optimum time for the adsorption, and the solute uptake rate suggests the probable mechanism of adsorption of adsorbate on the surface of the adsorbent. It also determines the rate limiting step of the adsorption.

Pseudo first-order model [32]:

The linear form of this model is given by:

$\ln \left(\mathrm{q}_{\mathrm{e}}-\mathrm{q}_{\mathrm{t}}\right)=\ln \mathrm{q}_{\mathrm{e}}-\mathrm{k}_{1} \mathrm{t}$

where, $\mathrm{q}_{\mathrm{e}}(\mathrm{mg} / \mathrm{g})$ and $\mathrm{q}_{\mathrm{t}}(\mathrm{mg} / \mathrm{g})$ are the amounts of dye adsorbed on the surface of the adsorbate at equilibrium and at any time $t$ ( $\mathrm{min})$, respectively; and $\mathrm{k}_{1}\left(\mathrm{~min}^{-1}\right)$ is the rate constant of the pseudo first-order adsorption.

Pseudo second-order model [33]:

The linear form is given by:

$\frac{\mathrm{t}}{\mathrm{q}_{\mathrm{t}}}=\left(\frac{1}{\mathrm{k}_{2}}\right) \mathrm{q}_{\mathrm{e}}+\frac{\mathrm{t}}{\mathrm{q}_{\mathrm{e}}}$

where, $\mathrm{k}_{2}(\mathrm{~g} / \mathrm{mg}$.min) is the rate constant of the pseudo second order equation. $\mathrm{q}_{\mathrm{e}}, \mathrm{q}_{\mathrm{t}}$ and $\mathrm{t}$ are the same as in pseudo first order model.

Intraparticle diffusion model [34]:

This model considers the intraparticle diffusion as the rate controlling step for adsorption. It is given by the following equation:

$\mathrm{q}_{\mathrm{t}}=\mathrm{k}_{\mathrm{id}} \mathrm{t}^{0.5}+\mathrm{C}$

where, $\mathrm{q}_{\mathrm{t}}(\mathrm{mg} / \mathrm{g})$ is the amount adsorbed at time $\mathrm{t}(\mathrm{min})$, and $\mathrm{k}_{\mathrm{id}}\left(\mathrm{mg} / \mathrm{g} \cdot \mathrm{min}^{0.5}\right)$ is the rate constant for the intraparticle diffusion model.

Boyd model [35]:

This model is applied to distinguish between the pore and film diffusion. This model is expressed as:

$\mathrm{B}_{\mathrm{t}}=-0.4977-\ln (1-\mathrm{F})$ 
where $B_{t}$ is the mathematical function of $F$, and $F$ represents the fraction of solute adsorbed at time $\mathrm{t}(\mathrm{h}), \mathrm{F}=\mathrm{q}_{\mathrm{t}} / \mathrm{q}_{\mathrm{e}}$

According to the model, if the plot $B_{t}$ versus $t$ passes through the origin, pore diffusion is the rate limiting step. Otherwise, the adsorption process is controlled by the film diffusion.

\section{MATERIALS AND METHODS}

\subsection{EQUIPMENT}

The concentration of the dye was measured using UV/visible spectrometer at a $\lambda_{\max }$ corresponding to the maximum absorption of the dye solution $\left(\lambda_{\max }=661 \mathrm{~nm}\right)$. The spectrophotometer used was UV-VIS spectrophotometer (UV mini-1240, Shimadzu). The aqueous samples were agitated using IKA Yellowline RS/OS 10 Control. The $\mathrm{pH}$ was measured using $\mathrm{pH}$ meter/ion meter (Accumet XL-60).

\subsection{PREPARATION OF ACTIVATED CARBON}

The date pits were obtained from a plant for processing and packing of dates in Madinah, Saudi Arabia. The pits were washed several times with tap water and three times with distilled water to remove dust and foreign materials. The pits were then dried overnight at $105{ }^{\circ} \mathrm{C}$ and then crushed and sieved to a uniform size of less than $1.0 \mathrm{~mm}$. The crushed date pits were mixed with zinc chloride at a mass ratio of $1: 1$ and then the mixture was left overnight. The impregnated precursor was divided into two parts. The first part was burnt in muffle furnace at $500{ }^{\circ} \mathrm{C}$ for 2 hours under nitrogen flow at a heating rate of $10 \mathrm{~K} / \mathrm{min}$. The product was washed several times with distilled water until the $\mathrm{pH}$ of the

washing water reached 6.0-7.0. The product was dried at $105^{\circ} \mathrm{C}$, crushed and sieved into a uniform size and kept in stoppered glass bottles for further use. The second portion of date pits was burnt using a microwave oven.
Microwave heating was carried out in a 2.45 $\mathrm{GHz}$ commercial microwave oven with suitable modifications. The oven has a power controller to select different power levels $(\mathrm{H}=$ high energy, $\mathrm{M}=$ medium energy, $\mathrm{MH}=$ medium high energy, and $\mathrm{ML}=$ medium low energy). The total energy of the oven is 600 $\mathrm{W}$. The burning was carried out in quartz crucibles placed on the turning plate contained in the chamber of the microwave oven. Nitrogen gas at a pre-set flow rate was used to purge any air in the chamber before the start of the microwave (for $12 \mathrm{~min}$ ) heating process, and it continued to flow through the chamber during the whole process (total radiation time was $12 \mathrm{~min}$ ). The flow of nitrogen was continued during the cooling stage $(10 \mathrm{~min})$. The product was washed using the same procedure that was applied previously.

\subsection{AdSORBate}

Methylene blue (MB) was obtained from $\mathrm{BDH}$. It was used as an adsorbate and was not purified prior to use. The stock dye solution was prepared by dissolving accurately $1 \mathrm{~g}$ of MB in $1000 \mathrm{ml}$ distilled water to obtain 1000 $\mathrm{mg} / \mathrm{L}$ dye. Working solutions were prepared by the dilution of stock solution using distilled water. The chemical structure of MB is illustrated in Figure (1).

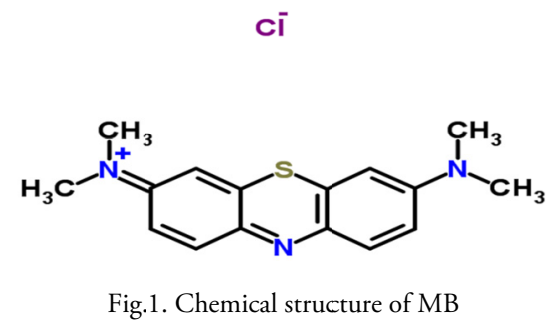

\subsection{ADSORPTION STUDIES}

\subsubsection{Effects of initial dye concentration}

Adsorption experiments were carried out by adding a fixed amount of sorbent $(0.12 \mathrm{~g})$ into $100-\mathrm{ml}$ Erlenmeyer flasks containing 50 $\mathrm{ml}$ of different initial concentrations (50- 
$1000 \mathrm{mg} / \mathrm{L}$ ) of dye solution. The experiment was performed at room temperature $\left(20 \pm 2{ }^{\circ} \mathrm{C}\right)$. Agitation was performed at 300 rpm for $240 \mathrm{~min}$ followed by settling for 20 $\min$.

\subsubsection{Effect of adsorbent dosage}

The effect of activated carbon dosage on the adsorption process was investigated by varying the sorbent dosage from 0.02 to $0.2 \mathrm{~g}$ of adsorbent (weighed to the fourth decimal point) per $50 \mathrm{~mL}$ of dye solution of initial concentration $150 \mathrm{mg} / \mathrm{L}$. The suspensions were shaken for $240 \mathrm{~min}$ at a speed of 300 rpm followed by settling for $20 \mathrm{~min}$. Samples were withdrawn from the supernatant and analyzed for residual MB.

\subsubsection{Effect of pH and point of zero charge}

The initial $\mathrm{pHs}$ of a series of dye solutions (50 $\mathrm{mL}$ each) were adjusted with $0.1 \mathrm{M} \mathrm{H}_{2} \mathrm{SO}_{4}$ or $0.1 \mathrm{M} \mathrm{NaOH}$ to form a series of $\mathrm{pH}$ ranging from 2 to 12. The initial concentration of the dye solutions were the same in all flasks (100 $\mathrm{mg} / \mathrm{L}$ ). The same mass of adsorbent was added to each flask. The mixtures were shaken at room temperature at $300 \mathrm{rpm}$. The mixtures were left to settle for $20 \mathrm{~min}$, and the supernatant was analyzed to determine the final concentration of MB.

The point of zero charge ( $\mathrm{pHPZC}$ ) for the adsorbent was determined by introducing 0.1 $\mathrm{g}$ of adsorbent into a set of $100 \mathrm{~mL}$ Erlenmeyer flasks containing $50 \mathrm{~mL}$ of $0.1 \mathrm{M}$ $\mathrm{NaCl}$ solution. Initial $\mathrm{pH}$ values of the set solutions were adjusted to $2,4,6,8,10$ and 12 by adding few drops of $\mathrm{H}_{2} \mathrm{SO}_{4}$ or $\mathrm{NaOH}$. The solution mixtures were allowed to equilibrate on the shaker for $48 \mathrm{~h}$. Then the suspension in each sample was filtered, and the final $\mathrm{pH}$ was measured again. The point of zero charge is determined from the curve relating the initial and final $\mathrm{pHs}$ (at initial $\mathrm{pH}$ $=$ final $\mathrm{pH}$ ).

\subsubsection{Effect of contact time}

Accurately weighed amount of activated carbon $(1.7 \mathrm{~g})$ was contacted with a dye solution volume of $1000 \mathrm{ml}$ and was stirred at room temperature for a given recorded time (2-300 $\mathrm{min})$. The initial concentration of dye was $100 \mathrm{mg} / \mathrm{L}$. At each time interval, $25 \mathrm{~mL}$ of the mixture were pipetted, and the final concentration was determined.

\section{RESULTS AND DISCUSSION}

\subsection{EFFECT OF INITIAL CONCENTRATION}

To investigate this effect, experiments were conducted with different concentrations of $\mathrm{MB}$, ranging from 50 to $1000 \mathrm{mg} / \mathrm{L}$, while keeping other parameters constant. The adsorbent is the activated carbon prepared using microwave radiation. The results of the study, depicted in Figure (2), illustrate the high dependence of the dye uptake and \% removal efficiency on the initial concentration of the adsorbate. The \% removal efficiency reached a value of $99 \%$ in the concentration range of $5-200 \mathrm{mg} / \mathrm{L}$ of the dye. This removal efficiency decreased to $41 \%$ for higher concentration $(1000 \mathrm{mg} / \mathrm{L})$. This must be taken into account when designing a system that treats highly polluted waste water.

A multi-stage system may be required in this case. On the contrary, the dye uptake increased when the concentration of the dye increased. This is due to the high driving force associated with the high concentration, which helps to transfer the dye molecules

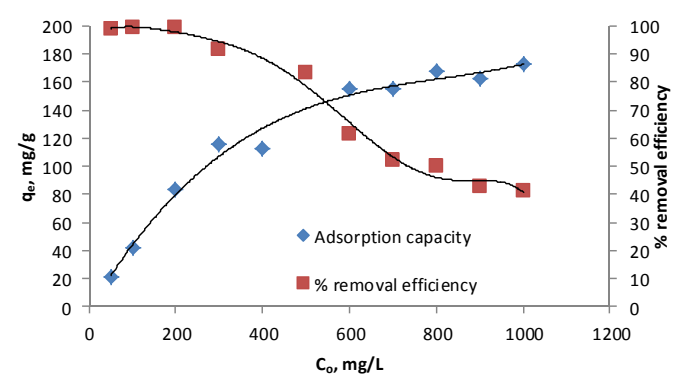

Fig.2. Effect of initial concentration on adsorption of $M B$ on $A C$ prepared by microwave 
from the bulk of the solution to the surface of the adsorbent. In addition, the increase in initial dye concentration will lead to the increase in the number of collisions between dye molecules and adsorbent, which enhances the sorption process [36]. The low $\%$ removal efficiency of the adsorbent at high concentration of the dye may be attributed to the limited number of adsorption sites that become saturated at a certain concentration. At low concentration, the ratio of number of dye molecules to adsorption sites is low, which enables all dye molecules to interact with the adsorbent surface [37].

\subsection{EFFECT OF ADSORBENT DOSAGE}

In the case of both types of activated carbon, the $\%$ removal of $\mathrm{MB}$ increased with the increase in the mass of adsorbent. However, the amounts of adsorbed dye per unit mass $\left(\mathrm{q}_{\mathrm{e}}\right)$ of the adsorbent decreased with the increase in the solid/solution ratio. Figures $3 \mathrm{a}$ and $3 \mathrm{~b}$ show that the adsorption of $\mathrm{MB}$ increases rapidly with the increase in the amount of adsorbent due to greater availability of the surface area at higher concentrations of the adsorbent and also due to the increase in the number of adsorption sites.

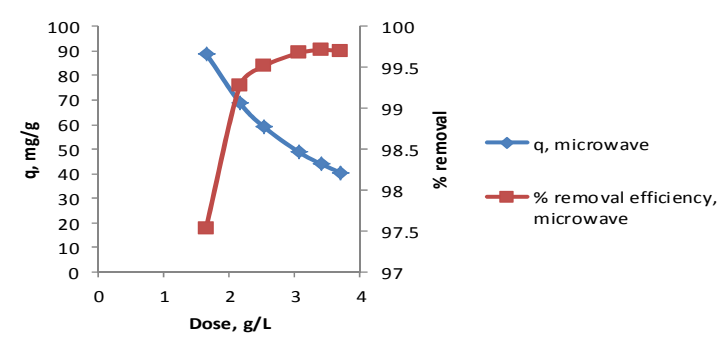

Fig.3a. Effect of mass change on adsorption of MB on AC prepared by microwave

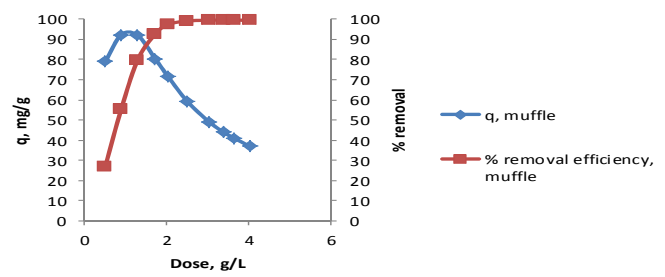

Fig.3b. Effect of mass change on adsorption of MB on AC prepared by muffle furnace
The significant increase in \% removal was observed when the dose was increased from 0.5 to $2.2 \mathrm{~g} / \mathrm{L}$ for microwave-prepared activated carbon and from 0.5 to $2.5 \mathrm{~g} / \mathrm{L}$ for muffle-furnace-prepared activated carbon. Any further addition of the adsorbent beyond the above-mentioned adsorbent/solution ratio did not cause any significant change in the adsorption. This may be due to the overlapping of adsorption sites as a result of overcrowding of adsorbent particles.

\subsection{EFFECT OF PH ON ADSORPTION EFFICIENCY}

The $\mathrm{pH}$ of the system exerts a profound influence on the adsorptive uptake of adsorbate molecules presumably due to its influence on the surface properties of the adsorbent and ionization/dissociation of the adsorbate molecule. Figure 4a shows the effect of initial $\mathrm{pH}$ of the dye solution on the uptake of the dye by activated carbon. It is clear from the figure that the increase in the $\mathrm{pH}$ of the solution in the range of 5.5 to 11.68 caused an increase in the adsorption capacity of the dye. This may be attributed to the amphoteric nature of activated carbon. This amphoteric nature depends on the surface functional groups of the carbon and also on point of zero charge (pHPZC) of the activated carbon [38]. Cationic adsorption is favored at $\mathrm{pH}>$ pHPZC, and the anionic adsorption is favored at $\mathrm{pH}<\mathrm{pHPZC}$. The value of pHPZC of the prepared activated carbon is 5.5 (Figure 4b), which explains the high adsorption capacity for the alkaline solutions. In alkaline media, the concentration of $\mathrm{OH}^{-}$

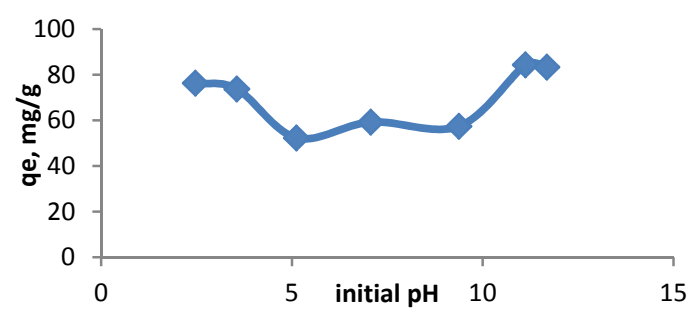

Fig.4a. Effect of $\mathrm{pH}$ of solution on dye uptake of $\mathrm{MB}$ on $\mathrm{AC}$ prepared by microwave 


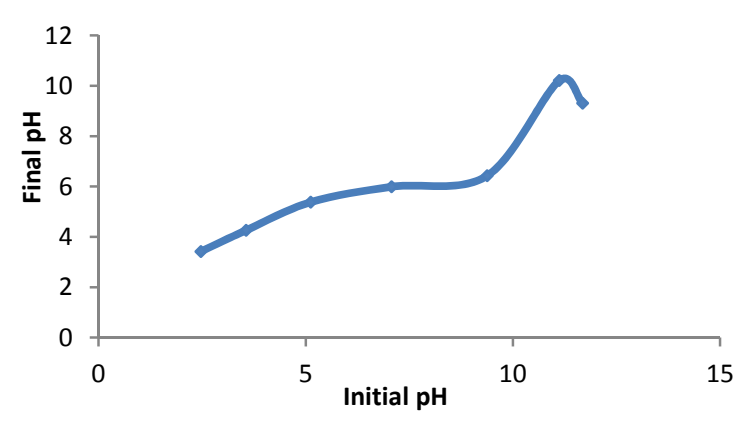

Fig.4b. Point of zero charge of the prepared activated carbon

will be high. These anions tend to attach themselves to the adsorbent surface. As the activated carbon surface is negatively charged at high $\mathrm{pH}$, a significantly strong electrostatic attraction appears between the negatively charged carbon surface and cationic dye molecule leading to maximum adsorption of dyes at high $\mathrm{pH}$ values. Moderate adsorption of $\mathrm{MB}$ was observed in the $\mathrm{pH}$ range of 2.53.6. At low $\mathrm{pH}$ values, the dye uptake was expected to decrease as the activated carbon and dye molecules are positively charged. However, the moderate adsorption in this low $\mathrm{pH}$ ranges may be attributed to another mechanism, e.g., hydrogen bonding and hydrophobic-hydrophobic mechanisms [39].

\subsection{ADSORPTION EQUILIBRIUM}

Generally, the adsorption models give valuable information about the adsorption capacity of the adsorbent used, describe the phenomenon governing the interaction of a certain substance (adsorbate) with the adsorbent in aqueous medium; retention, release or mobility, and help in providing necessary information for the design of both batch and continuous systems [40, 41, 42]. As shown in Table (1), according to $\mathrm{R}^{2}$ values, the isotherm models fit the experimental data for microwave-prepared activated carbon generally well in the following order: Langmuir, D-R, and Freundlich. The same order is attained according to $\mathrm{X}^{2}$. Furthermore, the value of correlation
TABLE 1: ADSORPTION PARAMETERS FOR THE APPLIED ADSORPTION MODELS

\begin{tabular}{|c|c|c|c|}
\hline \multirow{3}{*}{ Isotherm } & \multirow{2}{*}{ Parameters } & \multicolumn{2}{|c|}{ Adsorbent } \\
\cline { 3 - 4 } & & Microwave & Muffle \\
& & $\mathrm{AC}$ & $\mathrm{AC}$ \\
\hline \multirow{4}{*}{ Langmuir } & $\mathrm{R}^{2}$ & 0.963 & 0.939 \\
& $\mathrm{X}^{2}$ & 1.798 & 1.981 \\
& $\mathrm{q}_{\mathrm{m}}$ & 113.4 & 87.23 \\
& $\mathrm{~K}_{\mathrm{L}}$ & 1.42 & 1.54 \\
& $\mathrm{R}_{\mathrm{L}}$ & 0.0047 & 0.0043 \\
\hline \multirow{4}{*}{ Freundlich } & $\mathrm{R}^{2}$ & 0.902 & 0.916 \\
& $\mathrm{X}^{2}$ & 9.574 & 13.59 \\
& $\mathrm{n}$ & 5.376 & 5.917 \\
& $\mathrm{~K}_{\mathrm{f}}$ & 57.41 & 50.582 \\
\hline \multirow{3}{*}{ Dubinin- } & $\mathrm{R}^{2}$ & 0.943 & 0.939 \\
Radushkevich & $\mathrm{X}^{2}$ & 7.025 & 3.812 \\
& $\mathrm{q}_{\mathrm{m}}$ & 104.27 & 82.52 \\
& $\mathrm{E}$ & 9.091 & 7.299 \\
\hline
\end{tabular}

coefficient for fitting the experimental data to Langmuir isotherm is considerably high (0.963), indicating a good fit of the Langmuir model to the adsorption of $\mathrm{MB}$ on the prepared activated carbon. The thermalprepared activated carbon has a slight change in model order. According to $\mathrm{R}^{2}$ and $\mathrm{X}^{2}$, the order was as follows: Langmuir, D-R, and Freundlich. It can be noticed that Freundlich represented the lowest fit for all the cases studied; for the two activated carbons and the two error methods. Figure (5) represents the fitting of the models to the experimental data. It can be depicted from the figure that for the case of low adsorbent to adsorbate ratio (high concentration of adsorbent in the solution), all the models best fit the experimental data. An increase in this ratio leads to a deviation between the experimental and calculated data.

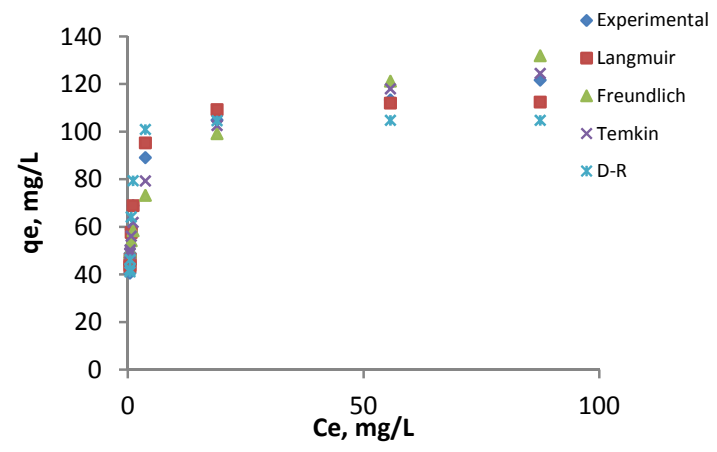

Fig.5. Fitting of the adsorption models to the experimental data 
As shown in Table (1), the maximum adsorption capacity for microwave-prepared activated carbon $\mathrm{q}_{\mathrm{m}}$ is $113.4 \mathrm{mg} / \mathrm{g}$, which represents a good value compared with that

obtained from activated carbon prepared by direct burning of the same precursor using the same chemical activator $(87.23 \mathrm{mg} / \mathrm{g})$. This means there is an increase in the adsorption capacity by a factor of 1.3.

According to Langmuir postulates, we expect the adsorption to be accompanied by monolayer coverage of the adsorbent with no interaction between the adsorbed molecules [43].

Since the experimental data is better represented by Langmuir isotherm, the essential feature of the isotherm, i.e., separation factor, must be investigated. The value of this factor indicated by Table (1) is 0.0047, which is less than unity. This indicates high favorability of the adsorption process. This very low value of separation factor (near to zero) is supported by the results obtained from fitting the data to D-R model that indicates the ion exchange adsorption process. This process is near to irreversible processes that are illustrated by a zero value of the separation factor [44]. This result implies the suitability of the prepared activated carbon for the adsorption of MB. The isotherm has L-shape, which indicates the high affinity of the prepared activated carbon to the dye [45]. Since the value of $\mathrm{X}^{2}$ for Freundlich model is the highest, we can conclude that Freundlich model cannot explain this adsorption system. Nevertheless, the data obtained from Freundlich does not contradict the data obtained from Langmuir. The value of $\mathrm{n}$ (known as heterogeneity factor) is greater than 1 (5.376), indicating a favorable adsorption process and possibly the occurrence of a chemical adsorption [37]. $\mathrm{k}_{\mathrm{f}}$ provides a rough indication about the adsorption capacity. The high value of $\mathrm{k}_{\mathrm{f}}$ presented in Table (1) assures the results obtained from Langmuir isotherm for the high adsorption capacity of the prepared activated carbon.

The Dubinin-Radushkevich (D-R) model is more general than Langmuir and Freundlich models. It estimates the energy of adsorption per unit mass of adsorbent, which gives an indication about the nature of the adsorption process: physical or chemical. It also estimates the adsorption capacity of the adsorbent under examination. The D-R model fits well to the experimental data. The maximum adsorption capacity calculated from this model is near to that obtained from Langmuir model. According to the energy of adsorption value $(\mathrm{E}=9.091 \mathrm{~kJ} / \mathrm{mole})$, the adsorption process follows the ion-exchange mechanism. The corresponding value for thermallyprepared activated carbon is $7.299 \mathrm{~kJ} /$ mole; this value is near to the ion exchange region. The adsorption capacities calculated from the model to the activated carbons are 104.27 and $82.52 \mathrm{mg} / \mathrm{g}$, respectively. The dye uptake of microwave-prepared activated carbon is 1.3 higher than that of thermally prepared activated carbon; the same ratio that was obtained using Langmuir model.

\section{ADSORPTION KINETICS}

The influence of contact time on the dye uptake of $\mathrm{MB}$ onto activated carbon was studied at two initial concentrations; 100 $\mathrm{mg} / \mathrm{L}$ and $300 \mathrm{mg} / \mathrm{L}$ in the range of $0-360$ min at room temperature $\left(20 \pm 2{ }^{\circ} \mathrm{C}\right)$. It can be seen from Figures 6 and 7 that the equilibrium was quickly attained in the case of low initial concentration. Within $2 \mathrm{~min}$, about $43 \%$ of $\mathrm{MB}$ was removed from the solution. Within $60 \mathrm{~min}$, the equilibrium was attained with a removal efficiency of $98 \%$. The plot may indicate that the two 
adsorptions follow two stages. The first stage is the fast characterization of the rapid attachment of $\mathrm{MB}$ to the surface or interlayer of the adsorbent. The second stage is the equilibrium stage. This can be attributed to the continuous decrease of driving force with time and the occupation of vacant sites at the early stage. Another reason is the probable repulsive force between the solute molecules adsorbed on adsorbent and that in the solution. For higher initial concentration (300 $\mathrm{mg} / \mathrm{L}$ ), the equilibrium was attained after approximately $300 \mathrm{~min}$ with a removal efficiency of $86 \%$, which indicates that the equilibrium time is dependent on the solution concentration. The adsorption process has a different profile. The first rapid stage is characterized by rapid attachment of $\mathrm{MB}$, and the slower second stage is characterized with the repulsive force and equilibrium stage. It is clear that the high concentration of adsorbate has a considerable effect on the adsorption mechanism. The adsorbate molecules will compete to be adsorbed on the surface of the adsorbent. The layer adjacent to the adsorbent will be thicker, hindering the diffusion process. The dynamics of sorption describes the rate of $\mathrm{MB}$ onto the activated carbon and the rate limiting step that controls the adsorption.

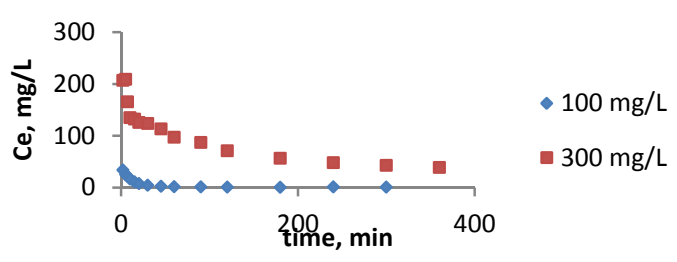

Fig.6. Effect of time on adsorption of MB on AC prepared by microwave

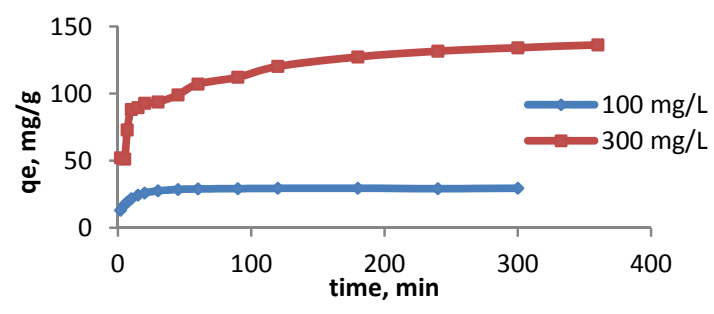

Fig.7. Effect of time on dye uptake of MB on AC prepared by microwave

Information on the dynamics of sorption is required for selecting optimum operating conditions for the full scale batch process. The sorption dynamics of the adsorption were tested with the Lagergren pseudo-first order, the second order, the intraparticle diffusion model, and liquid film diffusion model. The conformity between experimental data and the model predicted values was expressed by the correlation coefficients.

It can be observed from Table (2) that the adsorption of $\mathrm{MB}$ at the two concentrations used fits pseudo second order kinetics better than the first order. This can be concluded by comparing the $\mathrm{R}^{2}$ values for both the models. The general rate of adsorption of $\mathrm{MB}$ indicated by $k_{2}$ is faster in the case of the lower concentration. However, the initial rate of adsorption indicated by the value of $\mathrm{h}$ is higher for the high concentration. The rate limiting step was determined by applying intraparticle diffusion and mass transfer diffusion models.

Webber and Morris [34] reported that if the intraparticle diffusion was involved in the adsorption process, then a plot of the square root of time versus the dye uptake would result in a linear relationship.

TABLE 2: KINETIC PARAMETERS FOR THE APPLIED KINETIC MODELS

\begin{tabular}{|c|c|c|c|c|c|c|c|}
\hline \multicolumn{2}{|c|}{ Pseudo first order } & \multicolumn{2}{c|}{ Pseudo-second order } & \multicolumn{2}{c|}{ Intraparticle diffusion } & \multicolumn{2}{c|}{ Liquid film diffusion } \\
\hline $100 \mathrm{mg} / \mathrm{L}$ & $300 \mathrm{mg} / \mathrm{L}$ & $100 \mathrm{mg} / \mathrm{L}$ & $300 \mathrm{mg} / \mathrm{L}$ & $100 \mathrm{mg} / \mathrm{L}$ & $300 \mathrm{mg} / \mathrm{L}$ & $100 \mathrm{mg} / \mathrm{L}$ & $300 \mathrm{mg} / \mathrm{L}$ \\
\hline $\mathrm{R}^{2}=0.68$ & $\mathrm{R}^{2}=0.987$ & $\mathrm{R}^{2}=0.999$ & $\mathrm{R}^{2}=0.997$ & $\mathrm{R}^{2}=0.582$ & $\mathrm{R}^{2}=0.854$ & & \\
$\mathrm{~K}_{1}=0.034$ & $\mathrm{~K}_{1}=0.011$ & $\mathrm{~K}_{2}=0.602$ & $\mathrm{~K}_{2}=0.292$ & $\mathrm{~K}_{\text {id }}=0.803$ & $\mathrm{~K}_{\mathrm{id}}=4.93$ & $\mathrm{~K}_{\mathrm{d}}=0.093$ & $\mathrm{R}^{2}=0.979$ \\
$\mathrm{q}_{\mathrm{e}}=9.97$ & $\mathrm{q}_{\mathrm{e}}=65.2$ & $\mathrm{q}_{\mathrm{e}}=33.3$ & $\mathrm{q}_{\mathrm{e}}=142.9$ & $\mathrm{C}=19.23$ & $\mathrm{C}=64.46$ & & \\
& & $\mathrm{~h}=667.6$ & $\mathrm{~h}=5967$ & & & \\
\hline
\end{tabular}


The particle diffusion would be the only controlling step if this line passes through the origin. The $\mathrm{R}^{2}$ value obtained from the experimental data using intraparticle diffusion model (Figure (8) and Table (2)) for the low concentration is low, indicating the poor representation of this model to the adsorption of $\mathrm{MB}$ on the adsorbent at this low concentration.

The examination of $\mathrm{R}^{2}$ obtained from mass transfer diffusion model for the same concentration (Figure (9)) revealed the high conformity of the adsorption to this model. However, the line representing the experimental data does not pass by the origin, which indicates that mass transfer diffusion model is the main model responsible for adsorption but it is not the only one. The positive value of intercept $\mathrm{C}$ is indicative of some degree of boundary layer control [46]. The relation between $q_{t}$ and $t^{0.5}$ may be represented by multi-linear shape. This may indicate that more than one process affects the dye adsorption. The first linear sharp part of the plot (Figure 8), indicating the fast adsorption process, may be attributed to the fast external surface adsorption and intraparticle diffusion. In the final stage, the diffusion starts to slow down due to the low adsorbate concentration in solution and resistance of the adsorbate molecules on the surface to the diffusion of more molecules.

For the higher concentration, $\mathrm{R}^{2}$ value for mass transfer model is high, indicating the involvement of mass transfer in the adsorption process. Since the line representing this model does not pass through the origin, another mechanism may also be involved. The $\mathrm{R}^{2}$ value for the intraparticle diffusion model is moderately high, which indicates that this model also plays a certain role in the adsorption process. The role of this model at a high concentration is greater than that at a

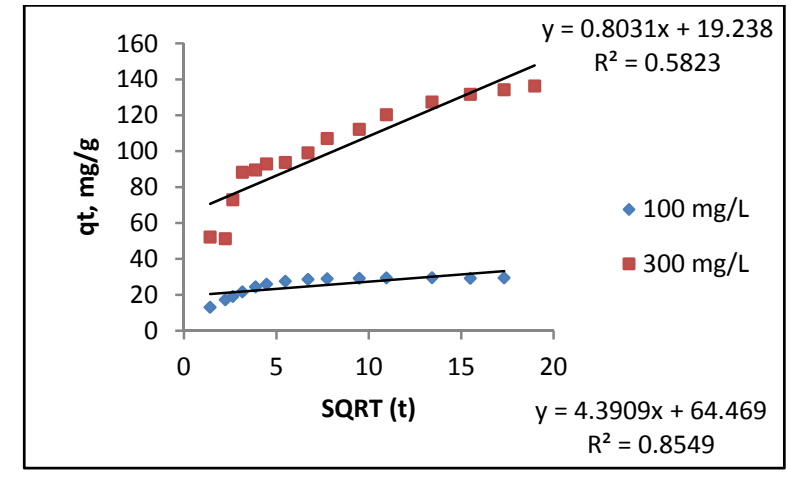

Fig.8. Intraparticle diffusion model for adsorption of $\mathrm{MB}$ on $\mathrm{AC}$ prepared by microwave

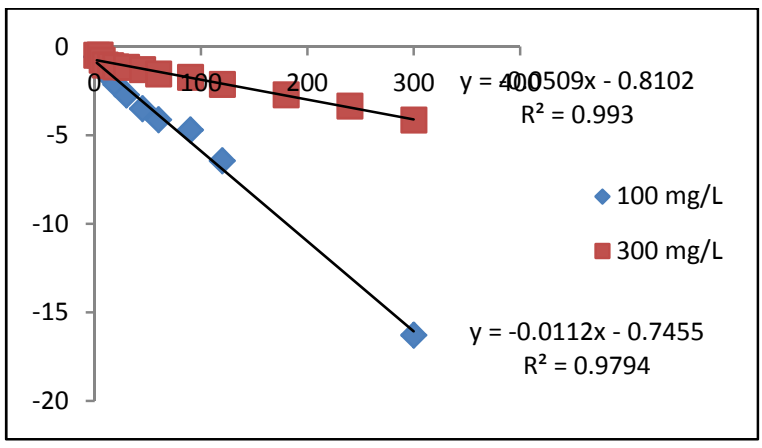

Fig.9. Film diffusion mass transfer model for adsorption of $\mathrm{MB}$ on AC prepared by microwave

low concentration, as illustrated by the value of $\mathrm{R}^{2}$. For the high concentration system, the plot of $\mathrm{q}_{\mathrm{t}}$ against $\mathrm{t}^{0.5}$, as shown in Figure (8), exhibits three sections.

The first represents a fast rate due to the high concentration of adsorbate in the solution and vacant adsorption sites. The rate of the second section is lower as it is the final equilibrium stage where intraparticle diffusion starts to slow down due to the extremely low adsorbate concentration left in the solution. The intercept, $\mathrm{C}$, indicating the boundary layer thickness, shows that rapid adsorption occurs within a very short time. The deviation from the origin may be due to the variation of mass transfer in the initial and final stages of adsorption. The constant $\mathrm{C}$ increased with increasing the dye concentration, which indicates the increase of the effect of the boundary layer and decrease of the effect of the external mass transfer and hence, increases the chance of internal mass transfer. 


\section{CONCLUSION}

The activated carbon evaluated in the present study was tested for adsorption of MB. The experimental equilibrium data were found to best fit Langmuir isotherm model, which indicates that the adsorption took place on a monolayer on the surface of adsorbent. The energy of adsorption calculated from D-R model was $8 \mathrm{~kJ} /$ mole. This indicates the ionexchange process and the strong interaction between the adsorbate molecules and the adsorbent surface. The adsorption capacity at the tested conditions were considerably high $(113.4 \mathrm{mg} / \mathrm{g})$ and comparable to activated carbons prepared by other researchers. Both initial $\mathrm{pH}$ and initial concentration of the aqueous solution have a considerable effect on the adsorption process. The adsorption process is described by second order model, and the adsorption is controlled by both intraparticle diffusion and liquid film diffusion. Based on the above-mentioned conclusions, activated carbon prepared from date pits is a promising adsorbent for the removal of pollutants from aqueous solutions.

\section{REFERENCES}

[1] Bhatnagar, A. and Minocha, A. K., Conventional And Non-Conventional Adsorbents For Removal Of Pollutants From Water - A Review, Indian Journal of Chemical Technology, 13, 203-217, 2006.

[2] Martínez de Yuso, A., Rubio, B. and Izquierdo, M. T., Influence Of Activation Atmosphere Used In The Chemical Activation Of Almond Shell On The Characteristics And Adsorption Performance Of Activated Carbons, Fuel Processing Technology, 119, 74-80, 2014.

[3] Hassan, A.F., Abdel-Mohsen, A.M. and Fouda, M.M.G., Comparative Study Of Calcium Alginate, Activated Carbon, And Their Composite Beads On Methylene Blue Adsorption, Carbohydrate Polymers, 102, 192- 198, 2014.

[4] Muthanna, J.A. and Theydan, S.K., Optimization Of Microwave Preparation Conditions For Activated Carbon From
Albizialebbeck Seed Pods For Methylene Blue Dye Adsorption, Journal of Analytical and Applied Pyrolysis, 105, 199-208, 2014.

[5] Hekmatzadeh, A.A., Jashn, A.K., Talebbeydokhti, N. and Kløve, B., Adsorption Kinetics Of Nitrate Ions On Ion Exchange Resin, Desalination, 326, 125-134, 2013.

[6] Sheela, T., Nayaka,Y.A., Viswanatha,R., Basavanna, S. and Venkatesha, T.G., Kinetics And Thermodynamics Studies On The Adsorption Of $\mathrm{Zn}(\mathrm{II})$, Cd(II) And $\mathrm{Hg}(\mathrm{II})$ From Aqueous Solution Using Zinc Oxide Nanoparticles, Powder Technology, 217, 163170, 2012.

[7] Neem, A., Westerhoff, P. and Mustafa, S., Vanadium Removal By Metal (Hydr)Oxide Adsorbents, Water Research, 41, 1596-1602, 2007.

[8] Ma, K., Cui, L., Dong, Y., Wang, T., Da, C., Hirasaki, G.J. and Biswal, S.L., Adsorption Of Cationic And Anionic Surfactants On Natural And Synthetic Carbonate Materials, Journal of Colloid and Interface Science, 408, 164-172, 2013.

[9] Sankararamakrishnan, N., Jaiswal, M. and Verma, N., Composite Nanofloral Clusters Of Carbon Nanotubes And Activated Alumina: An Efficient Sorbent For Heavy Metal Removal, Chemical Engineering Journal, 235, 1-9, 2014.

[10] Sari, A.,Mustefa, D. and Tuzen, M., Equilibrium, Thermodynamic And Kinetic Studies On Adsorption Of Sb(III) From Aqueous Solution Using Low-Cost Natural Diatomite, Chemical Engineering Journal, 162, 521-527, 2010.

[11] Ofomaja, A.E., Kinetics And Pseudo Isotherm Studies Of 4-Nitrophenol Adsorption Onto Mansonia Wood Sawdust, Industrial Crops and Products, 33, 418-428, 2011.

[12] Hegazi, A.A., Removal Of Heavy Metals From Wastewater Using Agricultural And Industrial Wastes As Adsorbents, HBRC Journal, 9, 276282,2013 .

[13] Nahil, M.A. and Williams, P.T., Surface Chemistry And Porosity Of Nitrogen-Containing Activated Carbons Produced From Acrylic Textile Waste, Chemical Engineering Journal, 184, 228-237, 2012.

[14] Adiuata, D., Wan Daud, W.M.A., and Aroua, M.K., Preparation And Characterization Of Activated Carbon From Palm Shell By Chemical 
Activation With K2CO3, Bioresource Technology, 98, 145-149, 2007.

[15] Amuda, O.S., Giwa, A.A., Bello, I.A., Removal Of Heavy Metal From Industrial Wastewater Using Modified Activated Coconut Shell Carbon, Biochemical Engineering Journal, 36, 174181,2007 .

[16] Hesas, R.H., Arami-Niya, A., Daud, W.M.A.W. and J.N. Sahu, Preparation Of Granular Activated Carbon From Oil Palm Shellby Microwave-Induced Chemical Activation: Optimizationusing Surface Response Methodology, Chemical Engineering Research And Design, 91, 2447-2456, 2013.

[17] Sun, Y. and Webley, P.A., Preparation Of Activated Carbons From Corncob With Large Specific Surface Area By A Variety Of Chemical Activators And Their Application In Gas Storage, Chemical Engineering Journal, 162, 883-892, 2010.

[18] Depci, T., Kul, A.R. and Onal, Y., Competitive Adsorption Of Lead And Zinc From Aqueous Solution On Activated Carbon Prepared From Van Apple Pulp: Study In Single- And MultiSolute Systems, Chemical Engineering Journal, 200-202, 224-236, 2012.

[19] Ahmaruzzaman, M. and Sharma, D.K., Adsorption Of Phenols From Wastewater, Journal of Colloid \& Interface Science, 287, 1424, 2005.

[20] FAOSTAT 2010. Statistical databases and datasets of the Food and Agriculture Organization of the United Nations. http://faostat.fao.org/default.aspx (June 2015).

[21] Chandrasekaran, M. and Bahkali, A.H., Valorization Of Date Palm (Phoenix Dactylifera) Fruit Processing By-Products And Wastes Using Bioprocess Technology - Review, Saudi Journal of Biological Sciences, 20, 105-120, 2013.

[22] Haimour, N. M. and Emeish, S., Utilization Of Date Stones For Production Of Activated Carbon Using Phosphoric Acid, Waste Management, 26, 651-660, 2006.

[23] Girgis, B.S. and El-Hendawy, A.A., Porosity Development In Activated Carbons Obtained From Date Pits Under Chemical Activation With Phosphoric Acid, Microporous and Mesoporous Materials, 52, 105-117, 2002.

[24] Alhamed, Y. A., Preparation And Characterization Of Activated Carbon From
Dates Stones, The 6th Saudi Engineering Conference, King Fahd University of Petroleum \& Minerals, Dhahran, Saudi Arabia. Proceedings, Volume 2, Chemical Engineering, pp: 461 - 472, 14- 17 December (2002).

[25] Rangabhashiyam,S., Anu,N. and Selvaraju, N., Sequestration Of Dye From Textile Industry Wastewater Using Agricultural Waste Products As Adsorbents, Journal of Environmental Chemical Engineering, 1, 629-641, 2013.

[26] Oliveira, L.C.A., Coura, C.V.Z., Guimarães, I.R. and Gonc alves, M., Removal Of Organic Dyes Using Cr-Containing Activated Carbon Prepared From Leather Waste, Journal of Hazardous Materials, 192, 1094-1099, 2011.

[27] Dotto,G.L. and Pinto, L.A.A., Adsorption Of Food Dyes Onto Chitosan: Optimization Process And Kinetic, Carbohydrate Polymers, 84, 2312382011.

[28] Forgacs, E., Cserha'ti, T. and Oros, G., Removal Of Synthetic Dyes From Wastewaters: A Review, Environment International, 30, 953-971, 2004.

[29] Langmuir, I., The Constitution And Fundamental Properties Of Solids And Liquids, Journal of American Chemical Society, 38, 22212295, 1916.

[30] Freundlich, H.M.F., Uber Die Adsorption in Losangen, Z. Phys. Chem. Frankfurt, 57A, 385470, 1906.

[31] Dubinin, M.M. and Radushkevic, L.V., Equation Of The Characteristic Curve Of Activated Charcoal, Proceedings of the Academy Of Sciences, Physical Chemistry Section USSR, 55, 331-333, 1947.

[32] Lagergren, S., About the Theory of So-Called Adsorption of Solution Substances, KungligaSrenskaVertensKaPsakademiens, Hand linger, 24, 147-156, 1998.

[33] Ho, Y.S. and McKay, G., A Comparison of Chemisorption Kinetic Models Applied To Pollutant Removal on Various Sorbents, Process Safety and Environmental Protection, 76, 332340, 1998.

[34] Weber, W.J. and Morris J.C., Kinetics of Adsorption on Carbon from Solution, Journal of Sanitary Engineering Division ASCE, 89, 31-59, 1963.

[35] Boyd, G.E., Adamson A.W. and Myers L.S, The Exchange Adsorption Of Ions From Aqueous Solutions By Organic Zeolites, Journal of the 
American Chemical Society, 69, 2836-2848, 1947.

[36] Anbia, M. and Saehi, S., Removal Of Acid Dyes From Aqueous Media By Adsorption Onto Amino-Functionalized Nonporous Silica SBA-3, Dyes and Pigments, 94, 1-9, 2012.

[37] Wang, L., Application Of Activated Carbon Derived From "Waste" Bamboo Clums For The Adsorption Of Azo Disperse Dye: Kinetic, Equilibrium And Thermodynamic Studies, Journal of Environmental Management, 102, 7987, 2012.

[38] Savova, D., Petrov, N., Yardim, M.F., Ekinci, E.,Budinova, T., Razvigorova, M. and Minkova, V., The Influence Of The Texture And Surface Properties Of Carbon Adsorbents Obtained From Biomass Products On The Adsorption Of Manganese Ions From Aqueous Solution, Carbon, 41 (10), 1897-1903, 2003.

[39] Newcombe, G. and Drikas M., Adsorption Of NOM Activated Carbon: Electrostatic And NonElectrostatic Effects, Carbon, 35, 1239-1250, 1997.

[40] Foo, K.Y. and Hameed, B.H., Insights Into The Modelin Of Adorption Isotherm Systems, Chemical Engineering journal, 156, 2-10, 2010.

[41] Ncibi, M.C., Applicability Of Some Statistically Tools To Predict Optimum Adsorption Isotherm After Linear And Non-Linear Regression Analysis, Journal of Hazardous Materials, 153, 207-212, 2008.
[42] Limousin, G., Gaudet, J.P., Charles, L., Szenknect, S., Barthes, V. and Krimissa, M., Sorption Isotherms: A Review On Physical Bases, Modeling And Measurement, Applied Geochemistry, 22, 249-275, 2007.

[43] Copello, G.J., Diaz, L.E. and Dall' Orto, V.C., Adsorption Of $\mathrm{Cd}(\mathrm{II})$ And $\mathrm{Pb}(\mathrm{II})$ Onto A One Step-Synthesized Polyampholyte: Kinetics And Equilibrium Studies, Journal of hazardous Materials, 217-218, 374-381, 2012.

[44] Ding, Y., Jing, D., Gong, H., Zhou, L.andYang, X., Biosorption Of Aquatic Cadmium(II) By Unmodified Rice Straw, Bioresource Technology, 114, 20-25, 2012.

[45] Iqbal, M.J. and Ashiq, M.N., Adsorption Of Dyes From Aqueous Solutions On Activated Charcoal, Journal of Hazardous Materials, 139(1), 57-66, 2007.

[46] Maksin, D.D., Kljajević, S.O., Đolić, M.B., Marković, J.P., Ekmeščić, B.M., Onjia, A.E. and Nastasovi, A.B., Kinetic Modeling Of Heavy Metal Sorption By Vinyl Pyridine Based Copolymer, Chemical Industry (HemijskaIndustrija), 66 (6),795, 2012. 
مقارنة إستخدام المايكروويف والمعالجة الحرارية لإنتاج الكربون المنشط من المخلفات الزراعية وإستخدامها

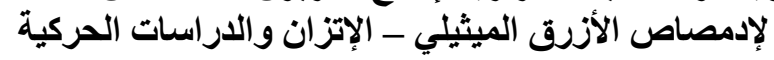

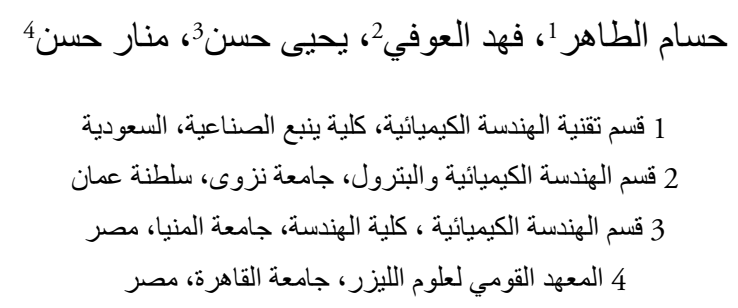

الملخص:

تم استخدام نوى التمور، و هى مخلفات زراعية تنتج على نطاق واسع، لإنتاج عينتين من الكربون المنشط. تم إعداد العينة الأولى عن طريق المعالجة الحرارية في 500 درجة مئوية لمدة ساعتين وأعدت الاخرى من خلال أشعة الميكروويف لمدة 12 دقيقة. كان المنشط الكيميائي للعينتين كلوريد الزنلك. تم التحقق من كفاءة العينتين نحو إدمصاص أزرق الميثيلين. وقد تم التحقق من تاثثر بعض العوامل على الإدمصاص كدرجة الحموضة الأوليةو التركيز الأولي لأزرق الميثيلين، وزمن الاتصال، وجر عة المادة المازة أيضا. طبقت نماذج الإتزان والحركية لفهم آلية عملية الامتزاز. وأظهرت النتائج أن إعداد الكربون المنشط باستخدام أثعة الميكروويف يعزز قدرة الإدمصاص بنسبة 30٪. . كان لتركيز محلول الصبغة والرقم الهيدروجيني آثار كبيرة على الامتصاص. تم العثور على درجة الحموضة المثلى لامتصاص لتكون 11. وجد ان نموذج لانجميور هو الأفضل لتمثيل الامتزاز و ان النموذج الحركي من الدرجة الثانية هو الذى يسيطر على عملية الإدمصاص. 